\title{
When wildcats feed on rabbits: an experimental study to understand the taphonomic signature of European wildcats (Felis silvestris silvestris)
}

Lluís Lloveras ${ }^{1}{ }^{*}$, Richard Thomas ${ }^{2}$, Alessandra Cosso $^{3}$, César Pinyol ${ }^{4}$, Jordi Nadal ${ }^{1}$

1. SERP. Departament de Prehistòria, Història Antiga i Arqueologia. Facultat de Geografia i Història. Universitat de Barcelona, C/ Montalegre 6, 08001 Barcelona, Spain.

2. School of Archaeology and Ancient History. University of Leicester. University Road, Leicester, LE1 7RH, UK.

3. Dipartimento di Storia, Scienze dell'Uomo e della Formazione. Università degli Studi di Sassari. Viale Umberto, 07100 Sassari, Italy.

4. Centre de fauna de Vallcalent. Departament d'Agricultura, Ramaderia, Pesca, Alimentació i Medi Natural. Camí de Vallcalent 63, 25195 Lleida, Spain.

${ }^{*}$ Corresponding author:

Lluís Lloveras

SERP. Departament de Prehistòria, Història Antiga i Arqueologia. Facultat de Geografia i Història. Universitat de Barcelona, C/ Montalegre 6, 08001 Barcelona, Spain

E-mail address: lluis\|loveras@ub.edu

\section{Abstract}

Studies of the feeding ecology of the European wildcat (Felis silvestris silvestris) demonstrate that leporids, mostly European rabbit (Oryctolagus cuniculus), dominate their diet in regions where they are present. The remains of wildcats have been found at Pleistocene and Holocene archaeological sites, raising the possibility that they actively accumulated leporid bones in caves and shelters shared with other terrestrial carnivores, raptors and humans. We present the first taphonomic study of rabbit remains consumed by this terrestrial carnivore, with the ultimate aim of understanding their role in bone accumulations at archaeological sites. An experimental study was carried out with a wildcat female, who was fed with nine complete rabbit carcasses. Non-ingested remains and scats were recovered for the analysis of anatomical representation, breakage and bone surface modification. This revealed that noningested remains and scats of the European wildcat can be discriminated from most 
other agents of accumulation. The referential framework provided will permit the discrimination of hominids and wildcats as agents of fossil accumulations of rabbits.

\section{Keywords}

Taphonomy; Wildcat; European rabbit; Small prey; Bone accumulators

\section{Introduction}

The wildcat Felis silvestris is a medium-sized carnivore that ranges over Africa, Europe and central Asia to India, China and Mongolia. It is the most common and widely distributed wildcat species in the world. In contemporary Europe, the European wildcat (Felis silvestris silvestris) presents a rather fragmented geographic distribution, ranging from the Iberian Peninsula to the eastern part of the continent (Stahl and Artois 1991; Sunquist and Sunquist 2002).

Wildcats consume a large diversity of prey from rodents to small ungulates, with a diet that varies geographically and is dependent upon prey availability (Lozano et al. 2006). Diet studies show that throughout its range, small rodents (mice, voles, rats, dormice) are the wildcat's primary prey; however, birds and reptiles may also be consumed. Most studies also evidence that in areas where abundances of leporids are high, normally European rabbits (Oryctolagus cuniculus) are preferred to other prey, constituting up to $70-90 \%$ of their diet (Condé et al. 1972; Gil-Sánchez et al. 1999; Sunquist and Sunquist 2002; Malo et al. 2004; Lozano et al. 2006; Lozano 2008). Wildcats can use small caves and rock shelters for sheltering and resting (Lozano 2008), and during breeding seasons in particular, they will accumulate prey leftovers and scats containing prey digested teeth and bone fragments within these dens.

The wildcat is first recorded in the fossil deposits of the Middle Pleistocene 250ky ago, during the Holsteinian Interglacial period (Wolsan 1993). The remains of wildcats have been found at many Pleistocene and Holocene archaeological sites, raising the 
possibility that these carnivores were active accumulators of rabbit bones in caves and shelters that they shared with other terrestrial carnivores, raptors and humans. Thus, taphonomic studies on rabbit remains consumed by this terrestrial carnivore are essential in order to identify its role as an agent responsible for rabbit remains assemblages on archaeological sites.

In the last decades, numerous taphonomic studies examining the role of small carnivores as possible agents of bone accumulation in archaeological deposits have been published (Schmitt and Juell 1994; Sanchis 2000; Mondini 2002; Cochard 2004; Gómez and Kaufmann 2007; Lloveras et al. 2008a; Mallye et al. 2008; Sanchis Serra and Pascual Benito 2011; Alvarez et al. 2012; Lloveras et al. 2012a; Stiner et al. 2012; Rodríguez-Hidalgo et al. 2013; Krajcarz and Krajcarz 2014; Rodríguez-Hidalgo et al. 2015; Amstrong 2016). They are especially relevant to the discussion about subsistence strategies and ways of life of hunter-gatherer communities. Particularly, in areas were European rabbits are present (Iberian Peninsula and Mediterranean regions), this prey is usually the most abundant taxon in the zooarchaeological record (Aura-Tortosa et al. 2002; Hockett and Haws 2002). Distinguishing anthropogenic and other predator accumulations is thus imperative, in order to assess the importance of small game exploitation in the past. Despite this fact, taphonomic studies on rabbit remains consumed by the European wildcat do not exist and its role as an agent responsible for bone accumulations at archaeological sites is unknown. The aims of this study are: firstly, to study the taphonomic patterns left by the European wildcat on non-ingested and scats rabbit remains and secondly, to put forward a series of criteria that can be used in archaeological samples to separate assemblages produced by wildcats from those accumulated by people or other predators.

\section{Materials and method}


To achieve our goals an experimental study was conducted with a wildcat female kept at the Wildlife Recovery Center of Vallcalent (Lleida, Spain), which was fed with 9 wild rabbits. The rabbit remains used in this study come from a farm specialized in breeding wild rabbits. The animals chosen were sub-adults with an average weight of approximately $1.5 \mathrm{~kg}$. During February of 2013 , the wildcat female, which was isolated in a naturalized enclosure of $150 \mathrm{~m} 2$, was fed with the complete rabbit carcasses. The rabbit leftovers not-ingested during feeding as well as the scats were collected and reserved for posterior analysis (Fig. S1).

All scats were rehydrated, water screened and disaggregated in a 1,5 mm. mesh. Non ingested remains, were still anatomically connected and attached to the skin of the rabbit so to facilitate removal of any remaining soft tissue, carcasses were boiled and cleaned under running water. The material was then ready for analysis.

The analytical methodology used in this study follows the same criteria applied in previous works that were carried out with leporid assemblages originated by different predators (Lloveras et al. 2008a, 2008b, 2009, 2012a, 2012b, 2014a, 2014b). The variables considered within each of the analytical parameters studied are presented below.

\subsection{Anatomical Representation}

The Number of Identified Specimens Present (NISP), Minimum Number of Elements (MNE) and Minimum Number of Individuals (MNI) were calculated as well as relative frequencies. Relative abundance was calculated using the formula advocated by Dodson and Wexlar (1979). In addition, proportions of skeletal elements were evaluated using the following ratios (Andrews 1990):

(a) PCRT/CR - the total number of postcranial elements (limb elements, vertebrae and ribs) compared with the total number of cranial elements (mandibles, maxillae and teeth). 
(b) PCRAP/CR - the total number of limb elements (long bones, scapulae, innominates, patellae, metapodials, carpals, tarsals and phalanges) compared with the total number of cranial elements (mandibles, maxillae and teeth).

(c) PCRLB/CR - the total number of postcranial long bones (humeri, radii, ulnae, femora and tibiae) compared with the total number of cranial elements (mandibles and maxillae).

Loss of distal limb elements was shown by two indices (Lloveras et al. 2008a):

(d) AUT/ZE - autopodia (metapodials, carpals, tarsals and phalanges) compared with zygopodia and stylopodia (tibiae, radii, ulnae, humeri, femora and patellae);

(e) Z/E - zygopodia (tibiae, radii and ulnae) compared with stylopodia (femora and humeri).

A further index compared anterior to posterior limb elements:

(f) AN/PO - scapulae, humeri, radii, ulnae and metacarpals compared with innominates, femora, tibiae and metatarsals.

\subsection{Breakage}

The breakage pattern was described by the maximum length of all identified skeletal elements. Percentages of complete elements, isolated teeth and articulated elements were calculated. For immature individuals, the diaphyses of long bones with unfused epiphyses were considered complete elements. Bone fragments were categorised depending on bone type:

- Patellae, carpals, tarsals and ribs were classified as complete (C) or fragmented (F).

- Phalanges were recorded as complete $(C)$, proximal $(P)$ or distal $(D)$ fragments. When the distinction between proximal or distal was not possible, they were recorded as fragment $(F)$.

- Vertebrae were registered as complete (C), vertebral body (VB), vertebral epiphysis (VE) or spinous process (SP). 
- Breakage of teeth was calculated separately for isolated and in situ elements (Fernández-Jalvo and Andrews 1992) and they were classified as complete (C) or fragmented $(F)$.

Breakage categories for long bones, metapodials, mandibles, crania, scapulae and innominates are fully described and illustrated in Lloveras et al. (2008a, Fig. 1). The presence of long bone cylinders (fragments of long bones with snapped ends resulting from consumption), and V-shaped and helical fractures (Villa and Mahieu 1991) were also recorded.

\subsection{Bone surface modifications}

All of the skeletal remains were examined both macro- and microscopically. Damage to the bone surface was observed under light microscope (x10-x40 magnification) with an oblique cold-light source.

\subsubsection{Digestion damage}

Different categories of digestion damage were applied to bones and teeth (FernándezJalvo and Andrews 1992; Lloveras et al. 2008a, 2008b, 2014c). Five categories of digestion were distinguished: null (0); light (1); moderate (2); heavy (3); and extreme (4). These were valued separately for bones and dental remains

\subsubsection{Tooth marks}

Damage to bone surfaces caused by teeth were noted and counted. Marks were classified as scoring, notches, tooth punctures/tooth pits and crenulated/fractured edges (Haynes 1980; Binford 1981; Brain 1981). Punctures and pits were also classified by their number (isolated or multiple) and distribution (unilateral - i.e. located on one surface - or bilateral) (Sanchis Serra et al. 2014).

\subsection{Density-mediated attrition}

Differential survival in relation to bone density was evaluated using the bivariate Spearman's rho correlation (Grayson 1984), taking into account the rabbit bone density data provided by Pavao and Stahl's (1999). 


\section{Results}

\subsection{Anatomical representation}

Table 1 shows the anatomical composition of the identified remains for both noningested ( $\mathrm{NI})$ and scat (SC) remains samples. A total of 1544 bones and teeth were determined, 1457 coming from $\mathrm{NI}$ sample and 87 from scats.

In the $\mathrm{NI}$ sample the estimated minimum number of individuals (MNI) was nine. The entire skeleton was represented except for the scapula. In absolute numbers phalanges $(27.6 \%)$, vertebrae $(14.5 \%)$, carpal/tarsal bones $(11.9 \%)$ and upper molars $(7.3 \%)$ were the most numerous elements $(\mathrm{N} \%)$. The relative abundance of skeletal elements $(\mathrm{RA} \%)$ is also shown in Table 1 and Fig. 1 . The mean value $(75.2 \%)$ was high, indicating a low loss of bones in the assemblage. The best-represented elements were the cranium, metatarsus, calcaneum, astragalus, femur and incisors; all of which displayed values of $100 \%$. Most skeletal elements $(77.3 \%)$ showed RA values over $75 \%$. Scapula, ribs and humerus were less well represented $(0 \%, 3.2 \%$ and $11.3 \%$ respectively).

The relative proportions of skeletal elements are shown in Table 2. Results indicate that there was a deficiency in the numbers of postcranial compared to cranial remains. Among the long bones, parts of the lower appendicular skeleton were more numerous than upper limb bones, with 1.3 times more elements from the hands and feet than the upper parts. The same goes for the relationship among zygopodium and stilopodium limb bones: there were 1.5 as many radii/ulnae/tibiae than humeri/femora. Posterior limb elements suvrived better than anterior elements.

In the SC sample the estimated minimum number of individuals (MNI) was only two individuals, indicating a loss of $77.8 \%$ of the individuals originally consumed. The bestrepresented elements were the scapula, forelimb bones and cranial remains (Table 1). Some vertebrae, ribs, metacarpals and phalanges were also registered; other skeletal 
elements were absent. The relative abundance of skeletal elements (RA\%) is also shown in Table 1 and Fig. 1. The mean value (15.2\%) was very low indicating an important loss of bones in the assemblage. The best-represented elements were the scapula (100\%), humerus/radius/ulna (50\% each) and cranium (50\%).

Proportion indices reveal that the scat sample contain more postcranial than cranial remains, more long bones than autopodium and more forelimb than hindlimb bones (Table 2); this pattern is the reverse of that seen in non-ingested remains.

\subsection{Breakage}

Breakage was limited in the NI sample, with $65 \%$ of specimens recorded over $10 \mathrm{~mm}$ in length. The percentage of complete bones was $92 \%$ and almost $24 \%$ of long bones were complete. The ulna, radius and humerus were the elements most affected by breakage (Fig. 2). Breakage categories are shown in Table 3.

- The most common complete long bones were the femur $(47.2 \%)$ and the tibia (36.1\%), while the humerus was never complete. The shaft plus distal epyphysis was most common among the fractured portions of humerus, radius and ulna. On the contrary, femur and tibia fragments were mostly repsented by proximal epyphysis portions. Most long bone fractures were mechanical, V-shaped and helical. Diaphyseal cylinders were not recorded in the assemblage.

- Metapodials were well preserved, $85.9 \%$ of the metacarpals and $83.9 \%$ of the metatarsals were complete. All the recovered frafments were parts of distal epyphysis.

- $\quad 19.2 \%$ of skulls survived complete and the most common fragments were parts of the neurocranium and maxillary bone.

- Mandibles were recovered fully intact in $48 \%$ of cases. Condylar process and body fragments with the incisive part had a higher rate of survival than other fragments.

- $73.9 \%$ of the innominates were complete. Among the fragments, only parts of the ischium were recovered. 
- Scapulae fragments were not recovered.

- Most of the vertebrae were complete (82.9\%). Fragments were represented mainly by the vertebral body and vertebral epiphyses.

- The ribs were scarce, they were intact in $57.1 \%$ of the cases.

- Carpals, tarsals and phalanges were complete in percentages above $94 \%$ in all cases.

- $\quad$ All teeth were placed "in situ" and they were always complete.

In the SC assemblage breakage was very high. This sample comprised mainly very small fragments, only $1.2 \%$ of bones displayed length values over $10 \mathrm{~mm}$ and only $11.5 \%$ of bones were complete. In addition, no complete long bones were recovered. In fact, the only complete bones were some phalanges and carpals (Fig. 2). Breakage categories are shown in Table 4.

- The long bones were only represented by fragments of humerus, radius and ulna. The proximal epyphysis was the most common among the fractured portions recovered.

- Metapodials were scarce and they were never complete.

- The skull was only represented by parts of the neurocranium.

- For the mandible only one fragment of the condylar process was recovered.

- Scapulae fragments always comprised the glenoid cavity (GC and GCN).

- The vertebrae were never complete. Fragments were mainly represented by vertebral body and spinous process.

- The ribs were fragmented in all cases.

- More than $47 \%$ of phalanges appeared complete. Only one complete carpal was recovered.

\subsection{Bone surface modifications}

\subsubsection{Digestion damage}


In the SC sample $98.6 \%$ of remains presented digestion damage with $47.9 \%$ exhibiting 'extreme' digestion and $39.7 \%$ exhibiting 'heavy' digestion damage; light digestion damage was recorded rarely (1.4\%, Fig. 2 and Table 1). Different bones were altered in similar proportions although vertebrae were damaged to a slightly greater extent. Normally, the entire surface of the bones was affected by digestion corrosion (Fig. 3) as a result of the high degree of breakage.

\subsubsection{Tooth marks}

In the $\mathrm{NI}$ sample, tooth marks were observed on 87 specimens (6\% of the sample). The most common form of damage was fractured edges $(\mathrm{N}=79,76.7 \%)$, followed by punctures $(\mathrm{N}=8,7.8 \%)$, pits $(\mathrm{N}=6,5.8 \%)$, crenulated edges $(\mathrm{N}=6,5,8 \%)$, and scoring $(\mathrm{N}=4,3.9 \%)($ Table 1, Fig. 4). On the whole, $1.2 \%$ of bones displayed tooth pits and/or punctures.

Tooth marks were mostly documented in the radius $(25.2 \%)$ and vertebrae $(18.4 \%)$. Tooth pits and punctures were recorded on: the mandible fossa; the shaft and distal epiphysis of the radium; the proximal epiphysis of the femur; the acetabulum and ilium of the innominate; and the vertebral body. In many cases different types of tooth marks were documented in the same specimen.

In the SC sample, as a consequence of the high degree of breakage and digestion damage, tooth marks were not found.

\subsection{Density-mediated attrition}

There was no statistically significant correlation between bone mineral density and the frequency of rabbit skeletal portions recovered in the NI and SC samples (rho=0.21, p= 0.429 and rho $=0.1, p=0.703$ respectively). This indicates that preservation of rabbit remains acummulated by the wildcat are generally unaffected by structural density mediated attrition (after Pavao and Stahl's 1999). 


\section{Discussion}

The taphonomic signal of the European wildcat has not been characterized in previous works. Results obtained in this study show that this small carnivore only removes a specific number of skeletal elements during feeding, with large parts of prey remaining unconsumed. Such behaviour can generate important accumulations of non-ingested bones that according to the data collected in the present study are characterized by: the lack or scarcity of scapulae, humeri and axial skeletal remains; the prevalence of cranial elements and greater survival of hindlimbs over forelimbs; high frequencies of whole bones; and scarcity of tooth pit/punctured bones.

The scat sample comprised only 87 identifiable remains, bones from scats were scarce and difficult to identify. Although the sample is small, bone assemblages accumulated from wildcats scats appear to be characterized by: an abundance of scapulae and forelimb bones; a prevalence of postcranial elements and greater survival of forelimbs over hindlimbs; high frequencies of small-sized fragmented bones; and almost $90 \%$ of remains affected by extreme and heavy digestion corrosion without the presence of tooth pit/punctured bones. This evidence demonstrates that wildcat rabbit accumulations may differ significantly, depending on the the origin of the assemblage (Tables 1 and 2). The fact that skeletal remains in wildcat scats are rare and highly fragmented reduces the liklihood that they will be recovered archaeologically.

It is clear that working with captive animals permit a major controll of different variables afecting experimentation. However, it has been pointed before for other larger carnivores, that captivity may influence predator behavior and how they modify faunal assemblages (Gidna et al. 2013). To take into acconunt the context in wich assemblages are originated is essential. Taking this in mind, we are aware that some bias may be produced concerning our results as they derive from a captive wildcat. Also the small size of the scats sample implies the need to be cautious with the results from ingested elements. Nevertheless, this research is the first in wildcat modifications, 
and this results are a first approach that may be very useful to researchers analising archaeological leporid assemblages.

\subsection{The wildcat and other predators}

The results of this research demonstrate that the taphonomic pattern left by wildcats on rabbits differs from other predators. To facilitate comparisons, Table 5 presents a summary of results obtained from different European rabbit predators, where the data have been collected using the same methods.

\subsubsection{Comparisons of anatomical representation profiles}

Values of anatomical representation indices obtained for the wildcat differ from nocturnal and diurnal raptors. In the wildcat NI remains sample, most skeletal elements display higher Relative Abundance than in all the raptors samples (Fig. 5). However, there are a few skeletal elements (e.g. the humerus and scapula) that are less well represented in the wildcat sample, than in raptor assemblages. In contrast, in the wildcat SC sample most skeletal elements are less well represented than in the raptor assemblages with the exception of scapulae and forelimb long bones, which are more abundant in the wildcat accumulation (Lloveras et al. 2008b, 2009, 2014b).

Comparisons with other terrestrial carnivores also show differences in anatomical representation such as the higher representation of cranial remains in the $\mathrm{NI}$ wildcat sample (Fig. 6). Long bones, particularly the femur, were also much better represented. Profiles of RA for wildcat, lynx and fox show that wildcats consume little of the rabbit skeleton, whereas the red fox destroys most bones and the lberian lynx is situated in an intermediate position. While inter-specific differences are less clear in the scat sample, they are still evident (Fig. 6). Lloveras et al. (2012a) reported that red fox accumulations were characterised by high values for the relative abundance of cranial remains and upper limb bones from both anterior and posterior limbs. All these 
elements are visibly scarcer in the wildcat SC sample. Chi-square test of independence were used for comparing survivorship of skeletal elements or their fragments showing that differences in the relative abundance of both taxa are statistically significant $\left(\chi^{2}=\right.$ 117.9, $\mathrm{P}<0.01, \mathrm{df}=12$ ). Comparison with the taphonomic signature of Iberian lynx scat samples also shows significant differences $\left(\chi^{2}=268.1, \mathrm{P}<0.01\right.$, df $\left.=12\right)$. Lynxes tend to accumulate larger numbers of cranial remains, innominate and hindlimb bones (Lloveras et al. 2008a). The scapula is the only skeletal element that is noticeably better represented in the wildcat scat accumulation.

These differences observed in the anatomical representation profiles of wildcat prey reflect the feeding behaviour of this carnivore. When feeding on rabbits, wildcats start consuming the meat located around the axial skeleton, forelimb bones and crania, and only a few fragments of bones are ingested (observed by researchers from Wildcat Breeding Center of Vallcalent).

\subsubsection{Comparisons of breakage patterns}

Observation of breakage patterns reveals a low degree of fragmentation in the wildcat $\mathrm{NI}$ sample: $65 \%$ of remains were over $10 \mathrm{~mm}$ and the percentage of complete bones was $92 \%$. These values indicate that the wildcat fragmented non-ingested remains less than diurnal and nocturnal raptors nests, where the percentage of remains over $10 \mathrm{~mm}$ were $45-50 \%$ and the percentage of complete bones 38-75\% (Schmit 1995; Lloveras et

al. 2009, 2012b, 2014b; Table 5). However, this trend is reversed with forelimb long bones. The ulna, radius and humerus were the elements most affected by breakage (the humerus was never recovered complete) in the wildcat sample with an average of $2.2 \%$ of complete elements (Table 3 ). This average was much higher in all raptor nest assemblages: $40 \%$ for eagle owl; $50 \%$ for Bonelli's eagle; and $33.4 \%$ for golden eagle (Schmit 1995; Lloveras et al. 2009, 2012b, 2014b). 
The scat sample was more affected by breakage than raptor accumulations, even than those originating from pellets which are always constituted of more fragmented elements. The percentage of complete bones and complete long bones obtained in the present study $(11.5 \%$ and $0 \%)$ is lower than the values recorded for Bonelli's eagles (59.6\% and $15.4 \%)$ and Spanish imperial eagles (27\% and $0 \%)$ pellets.

With regards to terrestrial carnivores, wildcat, Iberian lynx and red fox leporid assemblages of $\mathrm{NI}$ remains are characterised by a low degree of fragmentation. The percentage of remains over $10 \mathrm{~mm}$, complete elements and complete long bones are similar for all carnivores. In fact, given that these completeness values can vary slightly as consequence of intraspecific variabiles (age of the prey, age of the predator, rabbit abundance, etc.) (Lloveras et al. 2012a; Rodríguez-Hidalgo et al. 2013, 2015), values obtained for different carnivores could overlap, making any distinction difficult.

Breakage patterns are also similar in wildcat, fox and lynx scat assemblages. Rabbit fragments from wildcat scats are slightly smaller than in scats of Iberian lynx and fox. Equally, the percentage of complete elements is higher in the lynx sample but practically the same in the red fox (Table 5). However, more studies of wider wildcat scat samples are required to confirm these subtle differences.

\subsubsection{Comparisons of bone surface modifications}

Different types of predators produce similar kinds of teeth/beak damage when feeding on rabbit carcasses. This study shows that in the NI sample, the percentage of bones with tooth damage $(6 \%)$ is similar to those recorded in raptor nest accumulations such as the Bonelli's (4.1\%) eagle or the Egyptian vulture (7.5-10.4\%) (Lloveras et al. 2014a, 2014b; Sanchis Serra et al. 2014). The percentage of tooth pits/punctures $(1.2 \%)$ is lower than the beak pits/punctures registered in European eagle owl nest accumulations $(2 \%)$ but higher than values obtained for Bonelli's eagle $(0.8 \%)$. However, values are too close to distinguish predators. The innominate, vertebrae, femora and mandibles were commonly affected by surface modifications in these 
studies. These bones were also affected in the wildcat sample, but most marks were documented on the radius $(25.2 \%)$. The presence of different types of tooth marks registered in the same specimen (related to gnawing damage) is uncommon in raptor accumulations.

Distinguishing the damage produced by different terrestrial carnivores is more challenging. The percentage of tooth pits/punctures has been defined as one of the best characteristics to discriminate between Iberian lynx and red fox leporid accumulations Different studies show that lynxes produce much less damage (0.8$1.8 \%)$ than foxes (9.5-19\%) (Cochard 2004; Lloveras et al. 2008a; Sanchis Serra and Pascual Benito 2011; Lloveras et al. 2012a; Rodríguez-Hidalgo et al. 2013, 2015).

On the whole, in the wildcat $\mathrm{NI}$ sample $1.2 \%$ of bones displayed tooth pits and/or punctures. This low percentage also places the wildcat far from the red fox but in the same range of damage expected for the Iberian lynx. One possible difference to explore between both carnivores could be the location of tooth marks. As noted above, in the wildcat most of marks were documented in the radius $(25.2 \%)$ and vertebrae $(18.4 \%)$, however in the lynx samples the tooth marks occurred most commonly in innominates (26\%) and tibiae (20\%).

Regarding digestion damage, the percentage of digested remains in the wildcat SC sample $(98.6 \%)$ is higher than values obtained for raptor nest accumulations (i.e. $68.8 \%$ for Eagle owl, $31.2 \%$ for Bonelli's eagle, Table 5), but similar to the percentage of digested bones in some raptor pellets (i.e. $98 \%$ for Spanish imperial eagle) and other terrestrial carnivore scat assemblages (where almost $100 \%$ of remains exhibit digestion damage). However, in the wildcat sample digestion damage is clearly more pronounced than in the raptor samples, with a higher percentage of remains affected by an extreme degree of damage ( $47.9 \%$ vs $5.6 \%)$. Digestion corrosion damage is also stronger in the wildcat sample than in the red fox and Iberian lynx scat accumulations (47.9\% vs $25 \%$ and $19.3 \%$, Table 5$)$. 


\section{Conclusions}

In this study we provide the first detailed taphonomic observations on rabbit remains accumulated by the European wildcat. The results obtained help to identify and classify the most important characteristics of rabbit bone assemblages created by this carnivore. Identifiable rabbit remains are scarce in scats. Non-ingested material is characterized by the lack/scarcity of the scapula, humerus and axial skeleton remains, whereas the scapula and forelimb bones are the most abundant elements in scats. Non-ingested remains are much less fragmented and show a high percentage of complete bones. Rabbit remains in scats are affected by extreme and heavy digestion corrosion. Tooth marks are scarce and only evident on non-ingested remains.

Comparisons between the taphonomic signature of European wildcat and other rabbit predators showed that there are great similarities especially between wildcats and other terrestrial carnivores. Nevertheless, damage caused by wildcats on rabbits differ sufficiently from modifications produced by foxes and Iberian lynxes. The biggest difference lies in the anatomical representation profile. The frequency of tooth marks also differs from foxes, which can generate much larger numbers of tooth pits/punctures than the wildcat, although it is close to the values obtained for the Iberian lynx.

On archaeological sites, assemblages dominated by non-ingested remains are the most likely to be encountered, however; results may vary depending on the relative proportion of remains derived from scats. In fact, archaeological assemblages most often result in complex palimpsests of depositional history, mixing debris from prehistoric human occupations with those from other processes, both geological and faunal (Enloe 2012). The use of the reference data obtined in this study and others of the kind, is one way of deciphering portions of complex depositions. The taphonomic pattern obtained with fossil assemblages will rarely match exactly to the taphonomic signature here described, precisely as a consequence of the existence of palimpsests 
that mixt signatures originated by different agents. However, the criteria presented in this study for both types of accumulations (scats and non-ingested) can help to assess the potential contribution of European wildcats in accumulating fossil rabbit remains on archaeological sites.

\section{Acknowledgements}

LI. Lloveras was funded by postdoctoral fellowships BP-A 003342011 and BPB-001402014 from the Secretaria d'Universitats i Recerca del Departament d'Economia i Coneixement de la Generalitat de Catalunya and COFUND programme (Marie Curie Actions). Financial support from research projects HAR2014-55131 from the Ministerio de Ciencia e Innovación (MICINN) and SGR2014-108 from the Generalitat de Catalunya are gratefully acknowledged.

\section{References}

Alvarez MC, Kaufmann CA, Massigoge A, Gutiérrez MA, Rafuse DJ, Scheifler NA, González ME (2012) Bone modification and destruction patterns of leporid carcasses by Geoffroy's cat (Leopardus geoffroyi): an experimental study. Quaternary International 278: 71-80.

Amstrong A (2016) Eagles, Owls, and Coyotes (Oh My!): Taphonomic analysis of rabbits and guinea pigs fed to captive raptors and coyotes. Journal of Archaeological Science: Reports 5: 135-155.

Andrews P (1990) Owls, Caves and Fossils. Natural History Museum, London.

Aura JE, Villaverde V, Pérez Ripoll M, Martínez Valle R, Calatayud PG (2002) Big game and small prey: Paleolithic and Epipaleolithic economy from Valencia (Spain). Journal of Archaeological Method and Theory 9: 215-267. 
Binford LR (1981) Bones: Ancient Men and Modern Myths. Ac. Press, New York.

Brain CK (1981) The Hunters or the Hunted? an Introduction to African Cave Taphonomy. University of Chicago Press, Chicago.

Cochard D (2004) Étude taphonomique des léporidés d'une tanière de renard actuelle: apport d'un référentiel à la reconnaisance des accumulations anthropiques. Revue de Paléobiologie 23: 659-673.

Condé B, Nguyen-Thi-Thu-Cuc, Vaillant F, Schauenberg $P$ (1972) Le régime alimentaire du Chat forestier (Felis silvestris , Schreber) en France. Mammalia 36: 112119.

Dodson P, Wexlar D (1979) Taphonomic investigations of owl pellets. Paleobiology 5: 275-284.

Enloe JG (2012) Middle Palaeolithic Cave Taphonomy: Discerning Humans from Hyenas at Arcy-sur-Cure, France. International Journal of Osteoarchaeology 22: 591602.

Fernández-Jalvo Y, Andrews P (1992) Small mammal taphonomy of Gran Dolina, Atapuerca (Burgos), Spain. Journal of Archaeological Science 19: 407-428.

Gidna A, Yravedra J, Domínguez-Rodrigo M (2013) A cautionary note on the use of captive carnivores to model wild predator behavior: a comparison of bone modification patterns on long bones by captive and wild lions. Journal of Archaeological Science 40: 1903-1910.

Gil-Sánchez J M, Valenzuela G, Sánchez J F (1999) Iberian wild cat Felis silvestris tartessia predation on rabbit Oryctolagus cuniculus: functional response and age selection. Acta Theriologica 44: 421-428.

Gómez G, Kaufmann C (2007) Taphonomic analysis of Pseudalopex griseus (Gray, 1837) scat assemblages and their archaeological implications. Journal of Taphonomy 5: 59-70.

Grayson DK (1984) Quantitative zooarchaeology. Academic Press, New York. 
Haynes G (1980) Evidence of carnivore gnawing on Pleistocene and Recent mammalian bones. Paleobiology 6: 341-351.

Hockett BS, Haws JA (2002) Taphonomic and methodological perspectives of leporid hunting during the Upper Paleolithic of the western Mediterranean basin. Journal of Archaeological Method and Theory 9: 269-302.

Krajcarz M, Krajcarz MT (2014) The red fox (Vulpes vulpes) as an accumulator of bones in cave-like environments. International Journal of Osteoarchaeology 24: 459475.

Lloveras LI, Moreno-García M, Nadal J (2008a) Taphonomic analysis of leporid remains obtained from modern Iberian Lynx (Lynx pardinus) scats. Journal of Archaeological Science 35: 1-13.

Lloveras LI, Moreno-García M, Nadal J (2008b) Taphonomic study of leporid remains accumulated by Spanish Imperial Eagle (Aquila adalberti). Geobios 41: 91-100.

Lloveras LI, Moreno-García M, Nadal J (2009) The Eagle Owl (Bubo bubo) as a leporid remains accumulator. Taphonomic analysis of modern rabbit remains recovered from nests of this predator. International Journal of Osteoarchaeology 19: 573-592.

Lloveras LI, Moreno-García M, Nadal J (2012a) Feeding the foxes: an experimental study to asses their taphonomic signature on leporid remains. International Journal of Osteoarchaeology 22: 577-590.

Lloveras LI, Moreno-García M, Nadal J (2012b) Assessing the variability in taphonomic studies of modern leporid remains from Eagle Owl (Bubo bubo) nest assemblages: the importance of age of prey. Journal of Archaeological Science 39: 3754-3764.

Lloveras LI, Nadal J, Moreno-García M, Thomas R, Anglada J, Baucells J, Martorell C, Vilasís D (2014) The role of the Egyptian Vulture (Neophron percnopterus) as a bone accumulator in cliff rock shelters: an analysis of modern bone nest assemblages from North-eastern Iberia. Journal of Archaeological Science 44: 76-90. 
Lloveras LI, Thomas R, Lourenço R, Caro J, Dias A (2014b) Understanding the taphonomic signature of Bonelli's Eagle (Aquila fasciata) on prey remains obtained from modern nests and pellets. Journal of Archaeological Science 49: 455-471.

Lloveras LI, Moreno-García M, Nadal J, Thomas R (2014c) Blind test evaluation of accuracy in the identification and quantification of digestion corrosion damage on leporid bones. Quaternary International 330: 150-155.

Lozano J (2008) Ecología del gato montés (Felis silvestris) y su relación con el conejo de monte (Oryctolagus cuniculus). PhD Thesis, Universidad Complutense de Madrid.

Lozano J, Moleón M, Virgós E (2006) Biogeographical patterns in the diet of the wildcat, Felis silvestris Schreber, in Eurasia: factors affecting the trophic diversity. Journal of Biogeography 33: 1076-1085.

Malo AF, Lozano J, Huertas DL, Virgós E (2004) A change of diet from rodents to rabbits (Oryctolagus cuniculus). Is the wildcat (Felis silvestris) a specialist predator? Journal of Zoology 263: 401-407.

Mallye JB, Cochard D, Laroulandie V (2008) Accumulations osseuses en péripherérie de terriers de petits carnivores: les stigmates de prédation et de fréquentation. Annales de Paléontologie 94: 187-208.

Mondini M (2002) Carnivore taphonomy and the early human occupations in the Andes. Journal of Archaeological Science 29: 791-801.

Pavao B, Stahl PW (1999) Structural density assays of leporid skeletal elements with implications for taphonomic, actualistic and archaeological research. Journal of Archaeological Science 26: 53-66.

Rodríguez-Hidalgo A, Lloveras LI, Moreno-García M, Saladié P, Canals A, Nadal J (2013) Feeding behaviour and taphonomic characterization of non-ingested rabbit remains produced by Iberian liynx (Lynx pardinus). Journal of Archaeological Science 40: 3031-3045. 
Rodríguez-Hidalgo A, Saladié P, Marín J, Canals A (2015) Expansion of the Referential Framework for the Rabbit Fossil Accumulations Generated by Iberian Lynx. Palaeogeography, Palaeoclimatology, Palaeoecology 418: 1-11.

Sanchis A (2000) Los restos de Oryctolagus cuniculus en las tafocenosis de Bubo bubo y Vulpes vulpes y su aplicación a la caracterización del registro faunístico arqueológico. Saguntum 32: 31-50.

Sanchis Serra A, Pascual Benito J (2011) Análisis de las acumulaciones óseas de una guarida de pequeños mamíferos carnívoros (Sitjar Baix, Onda, Castellón): implicaciones arqueológicas. Archaeofauna 20: 47-71.

Sanchis Serra A, Real Margalef C, Morales Pérez JV, Pérez Ripoll M, Tormo Cuñat C, Carrión Marco Y, Pérez Jordá G, Ribera Gómez A, Bolufer Marqués J, Villaverde Bonilla V (2014) Towards the identification of a new taphonomic agent: an analysis of bone accumulations obtained from modern Egyptian vulture (Neophron percnopterus) nests. Quaternary International 330: 136-149.

Schmitt DN (1995) The taphonomy of golden eagle prey accumulations at Great Basin roosts. Journal of Ethnobiology 15: 237-256.

Schmitt DN, Juell KE (1994) Toward the identification of coyote scatological faunal accumulations in archaeological contexts. Journal of Archaeological Science 21: 249262.

Stahl P, Artois M (1991) Status and Conservation of the wild cat (Felis silvestris) in Europe and around the mediterranean rim. Council of Europe Press, Strasbourg.

Stiner MC, Munro ND, Sanz M (2012) Carcass damage and digested bone from mountain lions (Felis concolor): implications for carcass persistence on landscapes as a function of prey age. Journal of Archaeological Science 39: 896-907.

Sunquist M, Sunquist F (2002) Wild Cats of the World. The University of Chicago Press, Chicago.

Villa P, Mahieu E (1991) Breakage patterns of human long bones. Journal of Human Evolution 21: 27-48. 
Wolsan M (1993) Évolution des carnivores quarternaires en Europe centrale dans leur contexte stratigraphique et paléoclimatique. L’Anthropologie 7: 203-222.

\section{List of Tables}

Table 1. Numbers $(\mathrm{N})$, percentages ( $\mathrm{N} \%$ ), minimum number of elements (MNE), minimum number of individuals ( $\mathrm{MNI}$ ) and relative abundance proportions (RA\%) of rabbit remains recovered from non-ingested and scat samples. Digestion damage: numbers and percentage of rabbit bones included in each digestion category. Tooth marks: numbers and location of tooth marks on rabbit remains. FRE: fractured edges, CRE: crenulated edges, SCO: scoring, NOT: notches, TPI: tooth pits, TPU: tooth punctures.

Table 2. Proportions of different parts of the skeleton in non-ingested ( $\mathrm{NI}$ ) and scat (SC) samples. Abbreviations are explained in Material and Methods section.

Table 3. Numbers and percentages of parts of the skeleton included in each breakage category for the non-ingested remains sample. Long bones, metacarpal and metatarsal bones were classified as: complete $(C)$, proximal epiphysis $(P E)$, proximal epiphysis + shaft (PES), shaft (S), shaft + distal epiphysis (SDE) and distal epiphysis (DE). Mandibles as: complete (C), incisive part (IP), mandible body + incisive part (MBI), mandible body (MB), mandible body + branch (MBB) and condylary process (CP). Crania as: complete (C), incisive bone (IB), incisive bone + maxilla (IBM), maxilla (M), zygomatic arch (ZA) and neurocranium (NC). Innominates as: complete (C), acetabulum (A), acetabulum + ischium (AIS), acetabulum + ischium + illium (AISIL), acetabulum + illium (AIL), ischium (IS) and illium (IL). Scapulae as: complete (C), glenoid cavity (GC), glenoid cavity + neck (GCN), glenoid cavity + neck + fossa $(\mathrm{GCNF})$, neck + fossa (NF) and fossa $(\mathrm{F})$. Vertebrae as: complete $(\mathrm{C})$, vertebral body (VB), vertebral epiphysis (VE) and spinous process (SP). Phalanges as: complete (C), 
proximal fragment, $(P)$, distal fragment $(D)$ and fragment $(F)$. Patellae, carpals/tarsals, calcanea, astragali, ribs and teeth as: complete $(C)$ and fragment $(F)$.

Table 4. Numbers and percentages of parts of the skeleton included in each breakage category for the scats remains sample. For abbreviations see caption of Table 3.

Table 5. Anatomical representation, breakage, digestion and teeth/beak marks for leporid remains accumulated by different types of predators compared with the results obtained for European wildcats in the present study.

\section{List of Figures}

Figure S1. Picture of the European wildcat involved in the experimental study. Examples of scats and non-ingested materials recovered.

Figure 1. Relative abundance of the different parts of the skeleton in the scats (SC) and non-ingested $(\mathrm{NI})$ remains samples. Abbreviations; man: mandible, cra: cranium, inc: incisors, u mol: upper molars, I mol: lower molars, hum: humerus, rad: radius, uln: ulna, fem: femur, tib: tibia, pat: patella, sc: scapula, inn: innominate, mtc: metacarpals, mts: metatarsals, phal $1 / 2$ : phalanges $1 / 2$, phal 3 : phalanges 3 , cal: calcaneum, ast: astragalus, c/t: carpal/tarsal, ver: vertebrae, rib: rib.

Figure 2. A: Percentage of complete rabbit remains in the scats (SC) and non-ingested (NI) remains samples. For abbreviations see caption to Figure 1. B: Percentage of skeletal remains included in each digestion category.

Figure 3. Examples of very fragmented and digested rabbit bones recovered from wildcat scats. Fragments of ulna $(B)$, radius $(C, D)$, humerus $(E)$, matapodial $(F)$, scapula $(G, H)$ and vertebrae $(I, J)$ afected by extensive digestion corrosion damage. 
Figure 4. Examples of tooth marks on rabbit bones recovered from wildcat noningested remains sample. Crenulated edges $(A)$, fractured edges $(B)$, pits and punctures (A, B, C, D).

Figure 5. Comparisons of relative abundance of different parts of the skeleton in raptors and wildcat (non-ingested and scats) samples. For abbreviations see the caption for Fig. 2.

Figure 6. Comparisons of relative abundance of different parts of the skeleton in red fox, Iberian lynx and wildcat (non-ingested and scats) samples. For abbreviations see the caption for Fig. 2. 